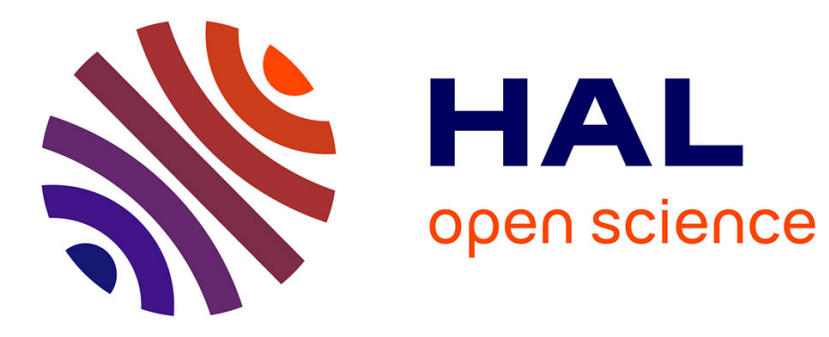

\title{
The Impact of Social Media on Cause-Related Marketing Campaigns
}

Julian Bühler, Natalia Cwierz, Markus Bick

\section{To cite this version:}

Julian Bühler, Natalia Cwierz, Markus Bick. The Impact of Social Media on Cause-Related Marketing Campaigns. 15th Conference on e-Business, e-Services and e-Society (I3E), Sep 2016, Swansea, United Kingdom. pp.105-119, 10.1007/978-3-319-45234-0_10 . hal-01702191

\section{HAL Id: hal-01702191 \\ https://hal.inria.fr/hal-01702191}

Submitted on 6 Feb 2018

HAL is a multi-disciplinary open access archive for the deposit and dissemination of scientific research documents, whether they are published or not. The documents may come from teaching and research institutions in France or abroad, or from public or private research centers.
L'archive ouverte pluridisciplinaire HAL, est destinée au dépôt et à la diffusion de documents scientifiques de niveau recherche, publiés ou non, émanant des établissements d'enseignement et de recherche français ou étrangers, des laboratoires publics ou privés.

\section{(c)(1)}

Distributed under a Creative Commons Attribution| 4.0 International License 


\title{
The impact of social media on cause-related marketing campaigns
}

\author{
Julian Bühler, Natalia Cwierz, and Markus Bick \\ ESCP Europe Business School Berlin, Berlin, Germany \\ \{jbuehler, mbick\} descpeurope.eu, \\ natalia.cwierzdedu.escpeurope.eu
}

\begin{abstract}
Traditional offline media channels have always served as a reliable backbone for all kinds of marketing campaigns. But with the emergence of new digitally-driven ways of communication, other contenders arise. Very prominent and fostered by ongoing technological advantage are social media services. In this empirical study, we analyze the interplay between two traditional offline channels, print and point-of-sale (PoS) advertising, and two leading social media services, Facebook and YouTube. These channels were used by the brand Volvic during a recent cause-related marketing (CRM) campaign. It supports local supply of drinking water in Ethiopia, and serves as the basis for our investigations. We developed an online survey and asked 114 participants for their perception of four alternating campaign displays. Based on the communication model of Te'Eni, we then calculate an ordinal logistic regression and results reveal that Facebook and YouTube can add significant value to CRM campaigns.
\end{abstract}

Keywords: Social Media, Facebook, YouTube, Caused-related Marketing, Ordinal Logistic Regression, Organizational Communication Model, Media Synchronicity Theory

\section{Introduction}

The statue of liberty is well-known as an iconic, prestigious symbol representing core values and convictions of the United States of America. More than three decades ago, this symbol was in bad conditions and restauration was inevitable, but high costs delayed the necessary operations. The financial service company American Express realized that they could draw significant positive attention by supporting the process and took over the lead of a what later was established as their "Historic Preservation Initiatives" program [1]. After few prior company initiatives in predominantly local markets had been executed [2], this was the first move into a concept nowadays recognized as cause-related marketing (CRM) [3].

Marketing strategies in general have to be adapted constantly to keep pace with people's continuously enhancing usage behaviors. This includes new communication platforms that got established with technological progress, especially social media service. 
Despite various understandings of the term behind it, social media includes social networks like Facebook, microblogging services like Twitter, video services like YouTube, platforms for social collaboration, and other social services or software.

In this article we shift from a broader marketing research perspective on general cause-related activities towards a selective comparative analysis of traditional and social media-driven channels. Our goal is to differentiate between these channel types by identifying unique key characteristics and bring the strength of both sides together. We contribute to this by an extensive analysis of the Volvic CRM campaign which was launched to call attention to the need of people in Africa for drinking water. The campaign was executed through two social media channels, Facebook and YouTube, and two traditional channels, print advertising and point-of-sale advertising. Based on media theories by Te'Eni [4] and Dennis et al. [5], we calculate separate ordinal logistic regressions for all channels two answer the main research question: "Can social media channels - compared to traditional channels - have a different impact on the user perception of cause-related marketing campaigns?"

Our research agenda is composed of a CRM literature review and utilization of two media theories for the Volvic case in section 2. We approach our research question with the help of an online questionnaire. Its setting is described as part of the research methodology in section 3. Survey results in section 4 lead to the discussion part, section 5 . We conclude this study in section 6 with an overview of potential avenues for future research.

\section{Theoretical perspective on CRM and social media integration}

\subsection{Evolution of CRM research}

The case of American Express in 1983 was constitutional for companies and the integration of CRM into many overall business strategies. But beside theses practical consequences, it also stimulated the academic research activities. In this section, we will provide a literature review of selected articles dealing with CRM and discuss how the role of media changed with the rise of social media in the last decade.

Researchers had begun studying CRM in the early to mid-80s and the first explorative articles emerged from existing corporate involvement examinations [6]. Soon, a critical perspective on CRM was added mainly based on trade literature, and arguments against it were based on predictions that traditional donations made by companies would significantly decrease [2]. With the continuous emergence of CRM, research was in need of a more precise structure. Varadarajan and Menon consolidated different understandings of what CRM represents, including sales promotion, a forming of philanthropy, corporate sponsorship, charity, and funding [7]. To their understanding, CRM is a "marketing activity" that contains elements of these concepts. They provided a first formal definition:

Cause-related marketing is the process of formulating and implementing marketing activities that are characterized by an offer from the firm to contribute a specified amount to a designated cause when customers engage in revenue-providing exchanges that satisfy organizational and individual objectives. [7] 
According to this definition, CRM is not limited to a certain industrial segment or branch. And indeed during the following years up to now, prominent companies of all sizes made intensive use of various CRM campaigns bearing in mind their resources. Prominent examples include Starbucks, the Coca Cola scholar program ${ }^{1}$ that awarded sustainable scholarships to students [8], or a Procter \& Gamble campaign called "Open Minds" 2 that supported children with special needs. CRM activities pervaded other areas like sports, e.g. a NIKE cooperation with Lance Armstrong's Livestrong foundation[9]. This example, however, also envisions potential risks which exist for companies, e.g. if bad headlines (here a doping incident) are associated with the campaign.

One of the main characteristics lies in the nature of CRM to produce benefit for many groups involved including nonprofit organizations that often receive the donations made by companies [3]. Because potential benefits are arguably obvious for donating companies and receiving organizations, a large CRM research stream evolved for a third group of entities, the customers. Roberts early reflected CRM from this perspective and identified a grown awareness of customers towards the companies' manufacturing processes [10]. For companies, CRM is also a direct reaction to demonstrate social responsibility for the environment in front of customers. Hence, they need to draw the excitement of customers and get them involved, as all "CRM campaigns should benefit from involvement" [11].

\subsection{Conceptualization of media research frameworks: Te'Eni and MST}

Regardless in which way interaction and communication between companies, donation-receiving organizations and consumers is perceived by the three respective entities, the various types of CRM all have a strong media integration in common. Media support through diverse channels has always been the key factor since the beginning of CRM campaigns, accompanied by additional actions [12].

Research on selection of appropriate media channels to initiate communication has a long tradition, starting with basic conceptualizations of information transfers between senders (or transmitters) and receivers by Shannon and Weaver [13]. A first framework for media selection that is still widely used today for theoretical foundations was the Media Richness Theory [14]. The differentiation ranged between lean media types like (bulk) e-mails and posters, and effective, rich types like face-to-face meetings or later, supported by technological progress, video conferences. These types, from a technical perspective, form the basis for Te'Eni's cognitive affective model category "medium" [4]. The communication process constituted in this model consists of a "goal", "strategies" to fulfill this goal which are selected by the sender and affected by the chosen "medium" and "message form". The combination of all four elements account for the overall level of "communication complexity" [15]. We will use this theoretical conceptualization of Te'Eni as the basis for the design of our empirical study and apply it to the case of Volvic in the next section.

\footnotetext{
http://www.coca-colacompany.com/stories/education/

http://nichestudio.com.my/openminds/
} 
Beside Te'Eni's model, the Media Synchronicity Theory (MST) was first introduced in 1999 at the HICSS conference [16] and completely postulated by Dennis et al. [5] in 2008. The authors predominantly focus on two transmission features which they call "conveyance" and "convergence". Conveyance describes the processing of a message that is of high content quality, is spread out slowly from multiples sources, and requires low synchronicity between both ends of the communication (sender and receiver). Convergence, on the other hand, takes the obverse characteristics: lower content quality, fast, and with a high level of synchronicity. Fur our purposes, we choose MST as a supporting concept, as we mainly focus on media selection and interaction of various media channels in this study. This focus is not originally intended by the MST authors who aim at explaining media performance with their model. Media selection was only part of a later extension of MST [17].

\subsection{CRM in the social media era: the case of Volvic}

Our digital perception changed over the last decade, triggered by the technological progress. Unidirectional devices like televisions turned into media centers and are connected with mobile devices, predominantly smartphones and tablets. Ley et al. [18] identified specific roles we as users attribute to our devices, and new concepts evolved and culminated with the rise of social media services [19]. Popular services we are familiar with including Facebook, YouTube, Twitter, Instagram, LinkedIn and countless other variations are established on the digital market nowadays. Kaplan and Haenlein categorize the concept of social media and understand services in this field as "a group of Internet-based applications that build on the ideological and technological foundations of Web 2.0, and that allow the creation and exchange of User Generated Content" [20]. We follow this definition for the purpose of our study.

CRM is used by companies to actively communicate their social engagement, on the one hand to draw attention to the corresponding cause, and on the other hand to allure new potential customers. According to the theoretical concepts of Te'eni and MST, media as the transmitting unit plays a key role. Companies not only participate in social media services, but also have begun to capitalize from expanding their general marketing strategy to the social media environment. Ongoing research in this field reveal that CRM initiatives increase users' brand awareness and their willingness to share their appreciation with friends through invitations [21]. Furlow [22] gives a case-study based overview of three CRM campaigns on Facebook by Procter \& Gamble (P\&G), Target, and Walmart. Among them, one (P\&G) describes the successful connection between an offline purchase of a product and online involvement in a bird rescue project via Facebook. This motivated us to deeper investigate the CRM campaign by Volvic which also made use of a combination of on- and offline channels.

Based on previous theoretical analyses, we decided to empirically investigate the CRM campaign " $1 \mathrm{~L}=10 \mathrm{~L}$ for Africa" of Danone via its brand "Volvic" in this study".

3 In cooperation with UNICEF, the campaign " $1 \mathrm{~L}=10 \mathrm{~L}$ for Africa" was also named "Drink 1 , Give 10" (http://drink1 give10.com/) 
The concept behind this campaign which started in 2005 is a pioneering idea of combining bottled water purchases with social engagement: For each liter of bottle Volvic water sold, the company obligates to provide 10 liters of drinking water for people in need from Ethiopia and other countries in Africa. The campaign was initially launched in Germany, and at later stages extended into other markets in industrialized countries, e.g. USA, UK, France or Japan. We used the CRM campaign of Volvic in this study as bottled water is an archaic, timeless product everyone is most likely confronted with. Water is also specifically eligible in the field of CRM and corporate social responsibility research, and other research projects successfully applied the combination of CRM and social media, e.g. Paek et al. [21]. The campaign itself was successful from an economic point of view as Danone could increase the brand awareness of Volvic and respective sales [23]. However, less is known about the different communication channels used in this campaign and their joint impact on the consumers. Hill and Moran [24] confront research findings from studies which analyzed on- and offline-driven social marketing campaigns. They reveal a contradiction between studies in terms of stronger behavioral influence caused by on- or offline campaigns. The Volvic case is suitable in this sense, as it was put into practice through four different channels: (1) The social network service Facebook, (2) the video platform YouTube, offline with (3) magazine and newspaper advertisement (print) as well as (4) in stores at the point-of-sale (PoS).

Table 1. Volvic's CRM campaign applied to Te'Eni's model of communication [4]

\begin{tabular}{|c|c|c|}
\hline Attribute & Explanations & Volvic campaign \\
\hline Goal & $\begin{array}{l}\text { Influence: "Attempting to influ- } \\
\text { ence behavior and attitude [...]" } \\
\text { Instruction Action: "Getting } \\
\text { the receiver to act according to } \\
\text { the sender's wishes." }\end{array}$ & $\begin{array}{l}\text { Drawing compassion for people } \\
\text { in need of drinkable water } \\
\text { Forwarding of the campaign; } \\
\text { Buying Volvic water }\end{array}$ \\
\hline Strategies & $\begin{array}{l}\text { Contextualization: "Provision } \\
\text { of affective components (emo- } \\
\text { tions, moods) in messages." } \\
\text { Attention focusing: "Directing } \\
\text { or manipulating the receiver's } \\
\text { information processing." }\end{array}$ & $\begin{array}{l}\text { Pictures (print) } \\
\text { Video (YouTube) }\end{array}$ \\
\hline Medium & $\begin{array}{l}\text { Channel capacity: The medi- } \\
\text { um's potential to transmit a high } \\
\text { variety of cues and languages. }\end{array}$ & $\begin{array}{l}\text { Picture + Text (Facebook) } \\
\text { Video (YouTube) } \\
\text { Picture (Print) } \\
\text { Positioner / Poster (PoS) }\end{array}$ \\
\hline $\begin{array}{l}\text { Message } \\
\text { Form }\end{array}$ & $\begin{array}{l}\text { Size: Number of semantic units. } \\
\text { Organization: The extent to } \\
\text { which the message is ordered to } \\
\text { support mutual } \\
\text { understanding. }\end{array}$ & $\begin{array}{l}\text { Limited to area of campaign (of- } \\
\text { fline); Unlimited (social media) } \\
\text { Interaction through comments } \\
\text { (YouTube, Facebook) } \\
\text { No interaction (Offline) }\end{array}$ \\
\hline
\end{tabular}


We contribute to CRM research in the way that we combine these four different communication channels without hierarchically preferring one over another. According to the conceptual model of Te'eni [4], we apply the Volvic campaign to the four pillars "goal", "strategies", "medium", and "message form" (Table 1).

It is necessary to analyze the whole Volvic campaign and, thus, to receive information on all four communication channels. In order to differentiate between the channels more adequately, we use the "conveyance" and "convergence" characteristics of MST. Both offline channels, print and PoS, can be characterized as rather conveyance ways to present a message. Multiple sources, i.e. advertisements in various magazines in newspapers, spread out the message of people in need of drinkable water slowly and passively, though intensively shaping "the understanding of the receiver" [15]. Depending on how Facebook and YouTube are used, both social media services can be classified as conveyance or convergence processes [25]. Volvic presented a video on YouTube showing children in Africa in front of already constructed fountains as a stimulus (element supporting conveyance), still allowing users comments below the video (element supporting convergence). On Facebook, users received, besides the picture also presented in the magazines and newspapers, additional news updates via the timeline by Volvic employees. A crosslink to the YouTube channel was also integrated, making Facebook a hybrid communication channel as well. Based on these classifications, we derived the following research model which we use as the basis for our empirical analysis (Fig. 1):

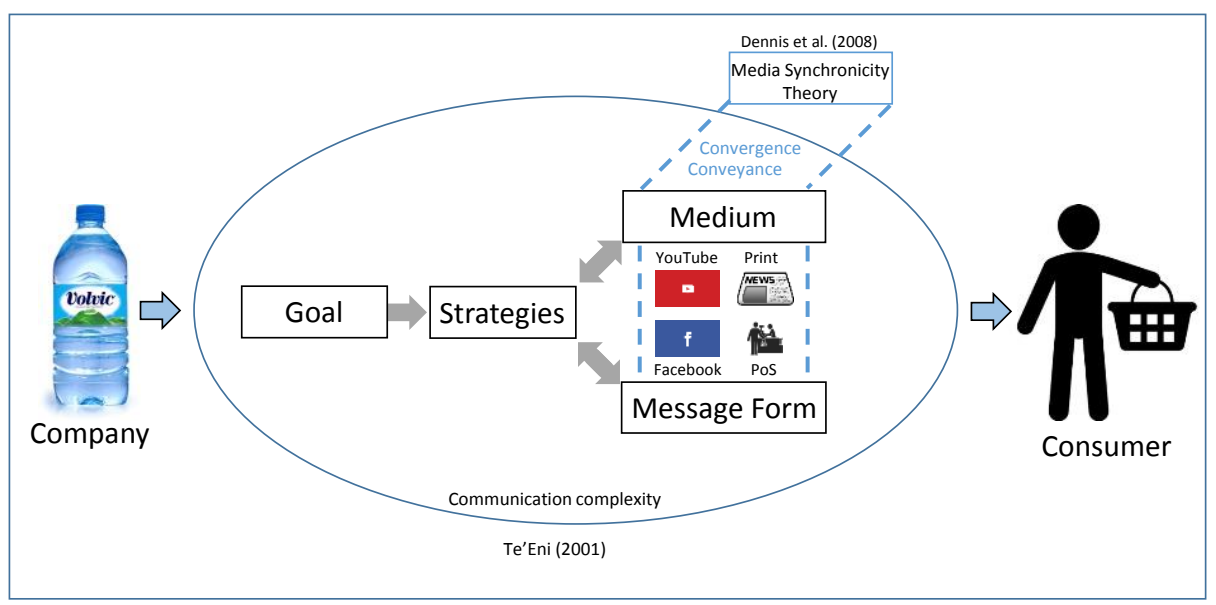

Fig. 1. Research model of the Volvic CRM campaign

\section{$3 \quad$ Research Methodology: Online questionnaire design}

Volvic's CRM campaign " $1 \mathrm{~L}=10 \mathrm{~L}$ for Africa" was simultaneously launched online on Facebook and YouTube, offline through various print advertisings in magazines, newspapers, and at point of sale. In order to analyze how consumers react on this stimulus, we decided to develop a questionnaire that reflects the individual perception of 
participants through all four communication channels. In line with its business model, YouTube was exclusively used by Volvic as a platform to share the campaign video. Thus, an online survey suited best for our purposes because it was possible to directly integrate the video within the survey system. We used the free open-source software "Limesurvey"4 to implement the survey.

Our questionnaire design followed a funnel approach design, narrowing down from general to specific, content-related questions [26]. It was split into several sections and started with initial questions on demographics ("age", "gender", "profession") including online behavior. In a second section we asked the respondents to assess their engagement in the society. Questions included participation in blood donations, waste separation, and ecology among others. It helped us to receive a general understanding of each participant's mindset before we focus on questions addressing the purchase behavior in terms of water, like frequency, brands, and Volvic in particular (e.g. "How often do you drink Volvic", "How often do you buy Volvic", "How well do you know Volvic as a brand").

We than addressed the core topic of our empirical investigation, Volvic's CRM campaign. For both the two offline channels as well as the two social media services, we combined the unique form of display used by Volvic with an identical set of homogeneous questions. Directly after presenting the campaign display, a "Timeline Screenshot" (Facebook), the integrated "campaign video" (YouTube), an original "advertising" from a magazine (print), and a visualization of a "positioner in a shop" (PoS), we asked participants to rate how emotionally provoked they are by the display. They then should state their "intention to purchase Volvic bottled water" and, depending on their answer, were ask to give reason for their decision. The full sequence of questions is visualized in Fig. 2.

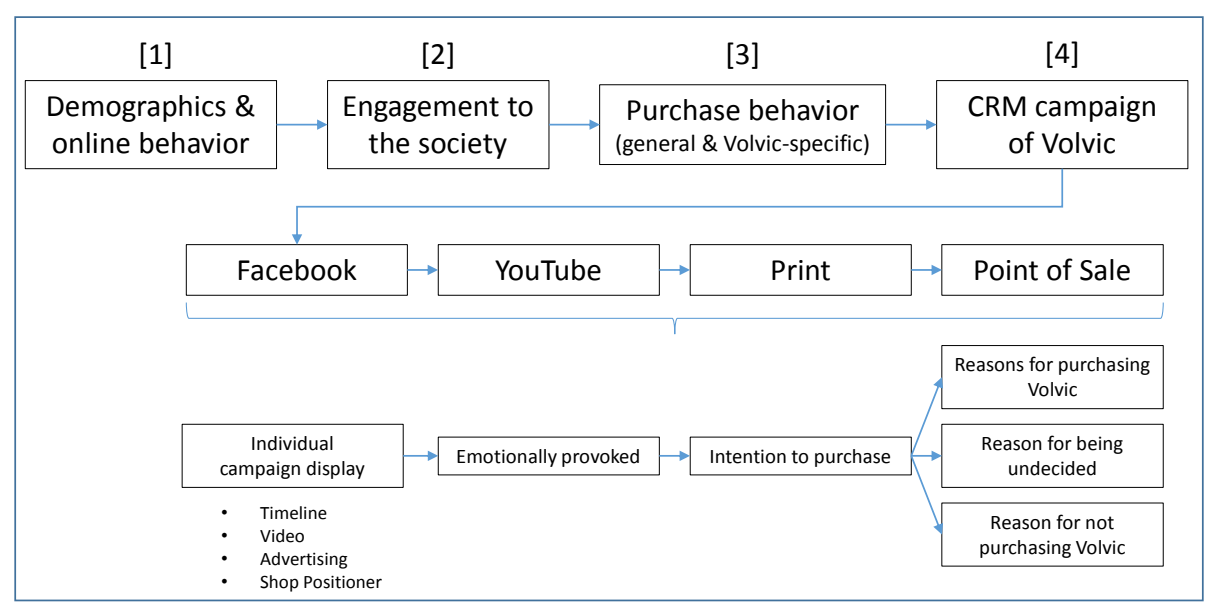

Fig. 2. Section and path of the Volvic CRM campaign questionnaire

4 https://www.limesurvey.org 
Volvic did not concentrate on a specific target group with their campaign. The cause of affordable, drinkable water in Africa should be recognized by as many consumers as possible. However, the campaigns on the respective markets varied in terms of language and content. Hence, we focused on Germany as the campaign was first started in this market and it is an important one with the highest amount of still mineral water exports for Volvic. We followed this approach and neither limited the questionnaire access to a specific target group. The link to the survey was distributed through various on- and offline channels including short URL aliases to ease mobile access. Most of the questions were designed as single choice checkboxes and, especially in the CRM campaign (4) as 5-point Likert scales in preparation for the ordinal logistic regression analysis. Both descriptive results and results of our regression analysis are discussed in the next section.

\section{Results}

\subsection{Initial descriptive outcomes}

Our online survey was accessible to the public in a timeframe between 20 November and 12 December 2015 on Limesurvey after a phase of two weeks in which we pretested and optimized especially the section where the campaigns were displayed. We received $\mathrm{n}=131$ responses that were completely filled. An initial analysis of these answers revealed that according to the response time that was tracked at runtime, 17 participants finished the survey in less than five minutes. However, the YouTube display - a video of 2.48 minutes' length - suggests that it is impossible to answer all questions appropriately in under five minutes. As data reliability was not given for them, we excluded these participants and received a final sample size of $n=114$.

To understand the demographic structure of our sample, we first analyzed the descriptive results of the first survey section. For this and all further calculations, the statistics software IBM SPSS Statistics 22 was used. A weak majority of participants are female $(n=68 ; 59.6 \%)$ compared to slightly fewer males $(n=46 ; 40.4 \%)$. On average our respondents are 26.84 (sd: 5.28 ) years old. From the initial data screening we could see that a minority of people were older than 35 years at the time of their responding. Thus, we decided to go deeper with our investigations and analyzed the age structure in a histogram. Compared to the normal distribution, we can see a potentially high kurtosis with a strong peak around mean. We calculated the values for measure of central tendency and divided the value for kurtosis (5.85) over its corresponding standard error (0.449). The excess value we received (13.01) indicates a heavy-tailed distribution [27]. The skewness of the sample is near normal distribution and only few older outliers influence the measurement. Overall, further calculations are not likely affected by the age distribution.

Results for online and social media behavior reveal a high penetration rate within our sample. Regular internet availability - a crucial barrier for CRM initiatives that are also run online - is no factor because nearly all participants $(n=112 ; 98.2 \%)$ accessed the internet more than once a day, the two remaining participants on average once a day. Both social media services are frequently used in this sample, with Facebook 
$(\mathrm{n}=96,84.2 \%)$ dominating over YouTube $(\mathrm{n}=45 ; 48.3 \%)$ regarding daily user visits (Fig. 3).

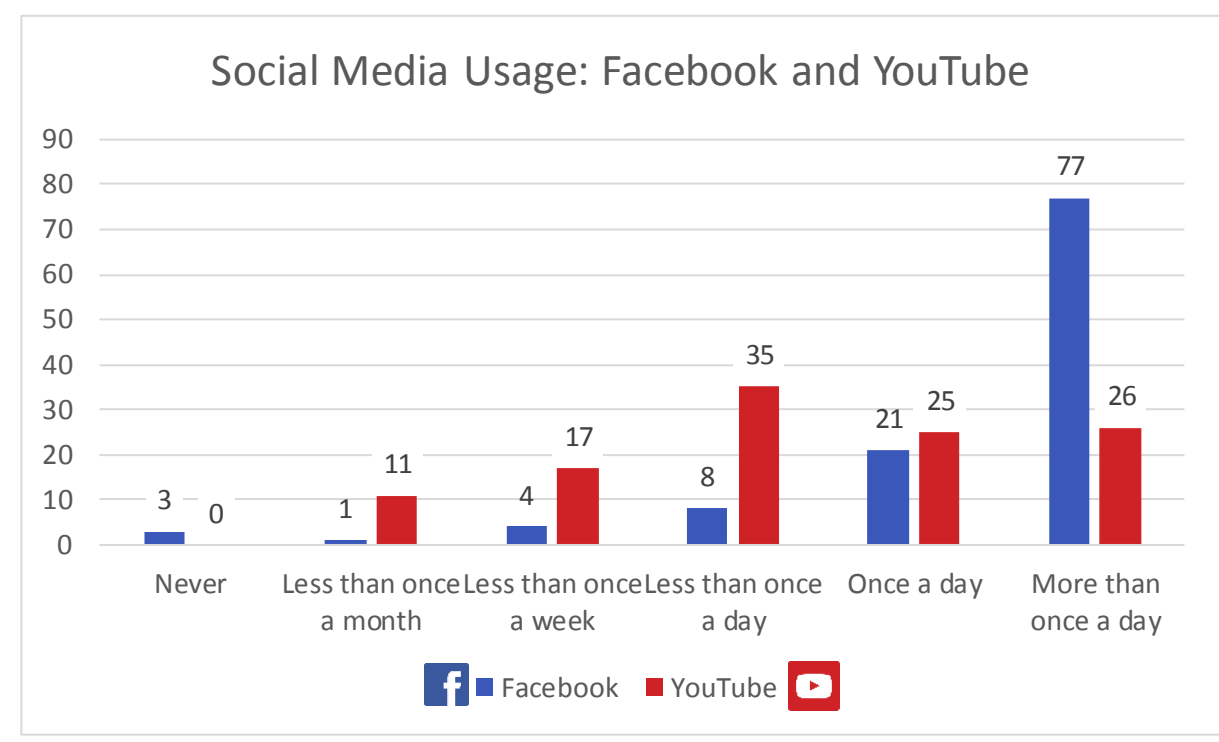

Fig. 3. Activity on Facebook and YouTube in our survey sample

Concerning the social and environmental engagement, the overall commitment is on an average level. On a 5-point Likert scale, a majority of $n=47(41.2 \%)$ participants indicate moderate involvement (score of 3). Waste separation was the individual activity with the highest level of commitment: 74 respondents (64.9\%) separate their waste regularly. Section three of the questionnaire addresses the purchase behavior with regard to water in general, and Volvic in particular. A majority of $73.7 \%(\mathrm{n}=84)$ buys water on a regular basis more than once in a month and $n=17$ (14.9\%) of the participants claim to buy large amounts of water ahead $(n=17)$. They favor a huge variety of 28 different local, national, and international brands. Only the remaining 13 respondents exclusively drink tap water. Volvic is the first choice of $17.5 \%(\mathrm{n}=10)$ participants, but it is in favor of as many as $36 \%(n=41)$ who state that they have a "positive" or "very positive" attitude towards the brand.

\subsection{Ordinal logistic regression analysis}

For the final core section 4 of our questionnaire, we calculated an ordinal logistic regression for all four communications channels, with Facebook and YouTube representing social media while print and PoS account for traditional channels. This regression type is dedicated to ordinal dependent variables which we use in all four scenarios [28]. "Willingness to buy Volvic" was measured on an ordinal scale with the answer options "Yes" and "No" as well as "Maybe" in between. As independent variables, we took into account one case-related and two basic demographic variables also used by 
Webb and Mohr [29] in their CRM study, "Social \& Environmental Engagement" as well as "Age" and "Gender". As a new variable to differentiate between social media and offline channels, we add "Emotional Agitation" which measures the participant's reaction after facing the four alternative channel displays (Table 2).

Table 2. Overview of regression variables

\begin{tabular}{|c|c|c|}
\hline Variable type & Name & Scale \\
\hline $\begin{array}{l}\text { Dependent } \\
\text { variable }\end{array}$ & $\begin{array}{l}\text { Willingness to buy Volvic } \\
\text { [alternated for each channel] }\end{array}$ & Ordinal [Yes | No | Maybe] \\
\hline $\begin{array}{l}\text { Independent } \\
\text { variables }\end{array}$ & $\begin{array}{l}\text { Age } \\
\text { Gender } \\
\text { Social \& Environmental } \\
\text { Engagement } \\
\text { Emotional Agitation [alternated] }\end{array}$ & $\begin{array}{l}\text { Continuous [in Years] } \\
\text { Dichotomous [male } \mid \text { female] } \\
\text { Interval [1-5 Likert scale] }\end{array}$ \\
\hline
\end{tabular}

We followed the ordinal regression procedure using the native PLUM estimation offered by SPSS. For all four channels, the regression was calculated individually with the corresponding values for the alternating independent and the dependent variable. We calculated the two social media models first and started with Facebook. First, we looked at the model fit and the deviance goodness-of-fit test indicated that the model was a good fit to the observed data as the Chi-Square is not significant $(\chi 2(188)=183.877, \mathrm{p}=.071)$. However, the Pearson value was significant though and we refer to the likelihood-ratio instead to decide. Here, the complete model with all four independent variables revealed a better fit than the intercept model $(\chi 2(4)=25.784$, $\mathrm{p}<0.001)$ indicating a suitable model fit. We proceeded to derive the regression equation for the Facebook case. In an ordinal regression with three categories ("No", "Maybe", "Yes"), two equations exist to describe the threshold between the categories. The regression then predicts with the help of probabilities in which category a person will be classified based on his or her characteristics (in terms of the independent variables) [30]. For Facebook, the following regression estimates result from the survey:

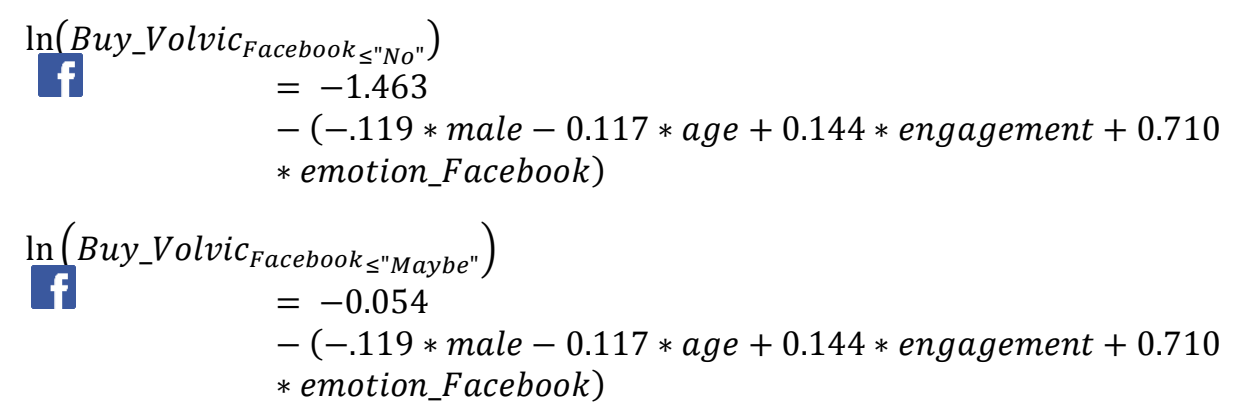

5 Equidistance and symmetry was controlled thus interval level of measurement can be assumed 
The negative log odd value coefficients result from the fact that the ordinal scale of the dependent variable "Willingness to buy" was categorized from $0=$ "No" to $2=$ "Yes". For age, an increase of one year results in an increase in the odds of considering to buy a bottle of Volvic water after seeing the Facebook campaign. The odds ratio is 0.889 and significant (Wald $\chi 2(1)=7.328, \mathrm{p}<0.01$ ). Emotional agitation after the display on Facebook has the highest coefficient in the equation and its impact (odd ratio: 2.034) is also highly significant (Wald $\chi 2(1)=14.980, \mathrm{p}<0.001$ ). We applied this procedure three more times for the CRM campaigns on YouTube, the print campaign and PoS. All results are summarized in tables 3 a-d:

Table 3(a-d). Ordinal logic regression results

\begin{tabular}{|c|c|c|c|c|c|c|c|}
\hline \multicolumn{2}{|c|}{ Facebook (FB) } & Estimate & Std. Error & Wald & df & Sig. & Exp_B \\
\hline \multirow{2}{*}{ 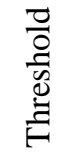 } & {$\left[\mathrm{FB} \_\right.$buy $=0$ ] } & -1.463 & 1.639 & 1.426 & 1 & 0.232 & 0.231 \\
\hline & {$\left[\mathrm{FB} \_\right.$buy $\left.=1\right]$} & -0.054 & 1.594 & 0.002 & 1 & 0.965 & 0.948 \\
\hline \multirow{5}{*}{ 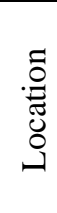 } & Age & -0.117 & 0.043 & 7.328 & 1 & 0.007 & 0.889 \\
\hline & Engagement & 0.144 & 0.209 & 0.473 & 1 & 0.492 & 1.155 \\
\hline & Emotion & 0.710 & 0.183 & 14.980 & 1 & 0.000 & 2.034 \\
\hline & {$[$ Gender $=0]$} & -0.119 & 0.386 & 0.095 & 1 & 0.758 & 0.888 \\
\hline & {$[$ Gender $=1]$} & $0^{\mathrm{a}}$ & & & 0 & & 1.000 \\
\hline
\end{tabular}

Link function: Logit. | a. This parameter is set to zero because it is redundant.

\begin{tabular}{|c|c|c|c|c|c|c|c|}
\hline \multicolumn{2}{|c|}{ YouTube (YT) } & Estimate & Std. Error & Wald & df & Sig. & Exp_B \\
\hline \multirow{2}{*}{ 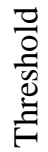 } & {$\left[\mathrm{YT} \_\right.$buy $=0$ ] } & -0.535 & 1.235 & 0.188 & 1 & 0.665 & 0.585 \\
\hline & [YT_buy = 1] & 1.340 & 1.242 & 1.163 & 1 & 0.281 & 3.819 \\
\hline \multirow{5}{*}{ 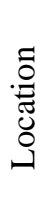 } & Age & -0.090 & 0.040 & 5.118 & 1 & 0.024 & 0.914 \\
\hline & Engagement & -0.320 & 0.216 & 2.194 & 1 & 0.139 & 0.726 \\
\hline & Emotion & 1.102 & 0.211 & 27.345 & 1 & 0.000 & 3.011 \\
\hline & {$[$ Gender $=0]$} & 0.053 & 0.404 & .0170 & 1 & 0.896 & 1.054 \\
\hline & {$[$ Gender $=1]$} & $0^{\mathrm{a}}$ & & & 0 & & 1.000 \\
\hline
\end{tabular}

Link function: Logit. | a. This parameter is set to zero because it is redundant.

\begin{tabular}{|c|c|c|c|c|c|c|c|}
\hline \multicolumn{2}{|c|}{ Print } & Estimate & Std. Error & Wald & $\mathrm{df}$ & Sig. & Exp_B \\
\hline 궁 & {$[$ Print_buy $=0]$} & -0.545 & 1.257 & 0.188 & 1 & 0.665 & 0.580 \\
\hline$\ddot{\Xi}$ & [Print_buy $=1]$ & 1.341 & 1.267 & 1.120 & 1 & 0.290 & 3.821 \\
\hline
\end{tabular}




\begin{tabular}{|c|c|c|c|c|c|c|c|}
\hline \multirow{5}{*}{ 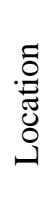 } & Age & -0.105 & 0.045 & 5.520 & 1 & 0.019 & 0.900 \\
\hline & Engagement & 0.011 & 0.217 & 0.002 & 1 & 0.961 & 1.011 \\
\hline & Emotion & 1.026 & 0.192 & 28.643 & 1 & 0.000 & 2.790 \\
\hline & {$[$ Gender $=0]$} & 0.229 & 0.400 & 0.327 & 1 & 0.568 & 1.257 \\
\hline & {$[$ Gender $=1]$} & $0^{\mathrm{a}}$ & & & 0 & & 1.000 \\
\hline
\end{tabular}

\begin{tabular}{|c|c|c|c|c|c|c|c|}
\hline \multicolumn{2}{|c|}{ Point of Sale (PoS) } & Estimate & Std. Error & Wald & df & Sig. & Exp_B \\
\hline \multirow{2}{*}{ 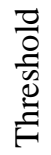 } & {$[$ PoS_buy $=0]$} & -2.164 & 1.350 & 2.569 & 1 & 0.109 & 0.115 \\
\hline & {$[$ PoS_buy $=1]$} & -0.330 & 1.340 & 0.061 & 1 & 0.805 & 0.719 \\
\hline \multirow{5}{*}{ 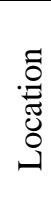 } & Age & -0.129 & 0.047 & 7.331 & 1 & 0.007 & 0.879 \\
\hline & Engagement & -0.152 & 0.228 & 0.446 & 1 & 0.504 & 0.859 \\
\hline & Emotion & 1.076 & 0.190 & 32.142 & 1 & 0.000 & 2.932 \\
\hline & {$[$ Gender $=0]$} & -0.476 & 0.410 & 1.347 & 1 & 0.246 & 0.621 \\
\hline & {$[$ Gender $=1]$} & $0^{\mathrm{a}}$ & & & 0 & & 1.000 \\
\hline
\end{tabular}

\section{Discussion}

The empirical results and especially those of our ordinal logistic regression contribute to finding an answer to the main research question which was initially drawn in the introduction. According to our data, social media channels can have a different impact on the outcome and perception of a cause-related marketing campaign. Results further reveal that companies can consider online channels, and especially social media services, as appropriate and adequate.

If we compare both social media services which we analyzed in this study, we see from the coefficients that Facebook has a lower overall impact compared to YouTube. Emotional agitation is for both services the most influencing trigger in the equation towards user perception that drives the buying intention in the end. This is supported by the strong statistical significances. However, contrasting both services with each other reveal differences. Videos as presented by Volvic on YouTube can touch users deeper than a mixture of various stimuli like it was the case on Volvic's Facebook appearance. In fact, if we take all four channels into account, this Facebook display underperforms. Both point-of-sale and print advertising displays drew more attention to the participants, resulting in stronger coefficient values.

Concerning the other input variables, gender and social engagement differences also contribute to the success of a CRM campaign, but play a minor role. Gender difference did not occur as the Volvic cause addresses a problem everyone is involved in and which does not include any gender-specific topics in particular. Age is an important factor and significant for all channels on the 1\% (PoS and FB) or 5\% (Print and 
YouTube) confidence interval. Estimates range between -0.09 (YouTube) and -0.129 (PoS). These low difference can be explained by the high kurtosis in our sample that sets up a rather centroid distribution.

As described in the theoretical section and visualized in our research model, we mainly lean on Te'Eni's model of communication and its focus on message transfer with the help of adequate media. Volvic's campaign can be assessed as successful not only regarding the overall perception by customers. Additionally, it can be seen as a positive example of how the interplay can work out between various on- and offline channels, or - to use Te'Eni's vocabulary - types of "media". Volvic's CRM campaign capitalized from the individual opportunities offered by the channels, thus transferring the "message" in effective manners. They presented a campaign video and offered user comments on YouTube which according to MST fulfils both conveyance and convergence. Our empirical results revealed that the impact of the Facebook campaign was rather low, but still existent. Most likely, that is also caused by the combination of conveyance and convergence and the fact that more users are active on Facebook.

In summary, our empirical findings reveal a strong impact of social media services on the perception of cause-related marketing campaigns. A key advantage is that most likely different target groups will be addressed. While PoS and print advertising in newspapers or magazines draw the attention of all user groups, social media can also address all these groups, but is specifically interesting for younger users [31]. Thus, a holistic coverage of all age groups can be established and CRM campaigns can capitalize from synergies of both sides. Instead of replacing traditional channels like print advertising or point-of-sale, companies should strive for a mélange of various channel types. By applying this "strategy", they can draw the attention of as many customers as possible through alternating displays and ultimately reach their pursued "goal" and the deepest impact.

\section{Conclusion}

In this study we contribute to the question if and in which way social media services like Facebook and YouTube can support a positive customer perception of cause-related marketing campaigns. Our empirical results reveal, based on ordinal logistic regression analyses, that social media services have a huge impact, but must not be seen isolated. These findings lead to more implications relevant for practitioners and raise new questions for further research projects.

Some practical insights for successful CRM campaigns can be derived from our findings. Companies should rely on social media services as many potential or active customers use these services and can be addressed easily. Key to achieving positive effects is an adequate display suitable for the respective service. For YouTube, a single video with an enabled comment function can be enough to gain these effects. Facebook, however, can primarily serve as a more general first place to go in the social media environment. With respect to their overall marketing strategy, companies benefit best from implementing social media services into it rather than replacing traditional services like print or PoS. 
From an academic perspective, this study helps social media research to position itself more appropriately. It provides researchers with a way to convey established communication frameworks like Te'Eni's model or MST to researchers of other fields. In particular, we aimed at getting better connected with established marketing research streams without obliterating its technological uniqueness. Also, we strengthened social media research in term of empirical investigations of effects caused by services like Facebook or YouTube. However, our findings are limited by some assumptions we had to make in our research design and which can serve as links to further research. First, we concentrated on two dominant services, but social media is a fast moving topic. Thus, more services on the rise, e.g. Twitter or Instagram, should be addressed. Second, we have a decent sample, but it is focused on German-speaking participants. Research projects based on our setting could analyze CRM campaigns in other countries, and focus on intercultural differences regarding social media utilization.

\section{References}

1. American Express Company, http://about.americanexpress.com/csr/pip.aspx

2. Ross Iii, J.K., Patterson, L.T., Stutts, M.A.: Consumer perceptions of organizations that use cause-related marketing. Journal of the Academy of Marketing Science 20, 93 (1992)

3. Berglind, M., Nakata, C.: Cause-related marketing: More buck than bang? Business Horizons 48, 443-453 (2005)

4. Te'Eni, D.: Review: A Cognitive-Affective Model of Organizational Communication for Designing it. MIS Quarterly 25, 251-312 (2001)

5. Dennis, A.R., Fuller, R.M., Valacich, J.S.: Media, Tasks, and Communication Processes: A Theory of Media Synchronicity. MIS Quarterly 32, 575-600 (2008)

6. Stroup, M.A., Neubert, R.L., Anderson, J.W.: Doing good, doing better: Two views of social responsibility. Business Horizons 30, 22-25 (1987)

7. Varadarajan, P.R., Menon, A.: Cause-Related Marketing: A Coalignment of Marketing Strategy and Corporate Philanthropy. Journal of Marketing 52, 58-74 (1988)

8. Slater, J.: Philanthropy for Profit. Far Eastern Economic Review 163, 48 (2000)

9. Nike's Corporate Interest Lives Strong: A Case of Cause-Related Marketing and Leveraging. Sport Marketing Quarterly 15, 184-188 (2006)

10. Roberts, J.A.: Will the real socially responsible consumer please step forward? Business Horizons 39, 79-83 (1996)

11. Grau, S.L., Folse, J.A.G.: Cause-Related Marketing (CRM). The Influence of Donation Proximity and Message-Framing Cues on the Less-Involved Consumer. Journal of Advertising 36, 19-33 (2007)

12. Smith, S.M., Alcorn, D.S.: Cause Marketing: A New Direction in the Marketing of Corporate Responsibility. Journal of Services Marketing 5, 21 (1991)

13. Shannon, C.E., Weaver, W.: The mathematical theory of communication. University of Illinois Press, Champaign, IL, US (1949) 
14. Daft, R.L., Lengel, R.H.: Organizational Information Requirements, Media Richness and Structural Design. Management Science 32, 554-571 (1986)

15. George, J.F., Carlson, J.R., Valacich, J.S.: Media Selection as a Strategic Component of Communication. MIS Quarterly 37, 1233-A4 (2013)

16. Dennis, A.R., Valacich, J.S.: Rethinking media richness: towards a theory of media synchronicity. In: Proceedings of the 32nd Annual Hawaii International Conference on Systems Sciences (HICSS), p. 1017 (1999)

17. Dennis, A.R., Fuller, R.M., Valacich, J.S.: Media synchronicity and media choice: Choosing media for performance. In: Hartmann, T. (ed.) Media choice. A theoretical and empirical overview. Routledge, New York (2009)

18. Ley, B., Ogonowski, C., Hess, J., Reichling, T., Wan, L., Wulf, V.: Impacts of new technologies on media usage and social behaviour in domestic environments. Behaviour \& Information Technology 33, 815-828 (2014)

19. Boyd, D.M., Ellison, N.B.: Social network sites: Definition, history, and scholarship. Journal of Computer-Mediated Communication 13, 210-230 (2007)

20. Kaplan, A.M., Haenlein, M.: Users of the world, unite! The challenges and opportunities of Social Media. Business Horizons 53, 59-68 (2010)

21. Jeong, H.J., Paek, H.-J., Lee, M.: Corporate social responsibility effects on social network sites. Journal of Business Research 66, 1889-1895 (2013)

22. Furlow, N.E.: Find us on Facebook: How Cause Marketing has Embraced Social Media. Journal of Marketing Development \& Competitiveness 5, 61-64 (2011)

23. Brei, V., Böhm, S.: ' $1 \mathrm{~L}=10 \mathrm{~L}$ for Africa': Corporate social responsibility and the transformation of bottled water into a 'consumer activist' commodity. Discourse \& Society 25, 3-31 (2014)

24. Hill, R.P., Moran, N.: Social marketing meets interactive media. International Journal of Advertising 30, 815-838 (2011)

25. Bühler, J., Lauritzen, M., Bick, M.: Social Media Communication in European Airlines. In: Proceedings of the 20th Americas Conference on Information Systems. Savannah, GA (2014)

26. Hair, J.F., Black, W.C., Babin, B.J., Anderson, R.E.: Multivariate data analysis. Prentice Hall, Upper Saddle River, NJ (2010)

27. Miles, J., Shevlin, M.: Applying regression \& correlation. A guide for students and researchers. SAGE Publications, London, Thousand Oaks, Calif. (2001)

28. Agresti, A.: Categorical data analysis. Wiley-Interscience, Hoboken, N.J. (2013)

29. Webb, D.J., Mohr, L.A.: A Typology of Consumer Responses to Cause-Related Marketing: From Skeptics to Socially Concerned. Journal of Public Policy \& Marketing 17, 226-238 (1998)

30. O'Connell, A.A.: Logistic regression models for ordinal response variables. SAGE Publications, Thousand Oaks, Calif. (2006)

31. van Bergh, J.d., Behrer, M.: How cool brands stay hot. Branding to generation Y. Kogan Page, London, Philadelphia (2011) 